\title{
Metabolic Effects of the Nocturnal Rise in Cortisol on Carbohydrate Metabolism in Normal Humans
}

\author{
Sean Dinneen, Aus Alzaid, John Miles, and Robert Rizza \\ Endocrine Research Unit, Mayo Clinic, Rochester, Minnesota 55905
}

\begin{abstract}
Glucocorticoid concentrations vary throughout the day. To determine whether an increase in cortisol similar to that present during sleep is of physiologic significance in humans, we studied the disposition of a mixed meal when the nocturnal rise in cortisol was mimicked or prevented using metyrapone plus either a variable or constant hydrocortisone infusion. When glucose concentrations were matched with a glucose infusion, hepatic glucose release $(2.6 \pm 0.2$ vs. $1.5 \pm 0.4 \mathrm{nmol} / \mathrm{kg}$ per $6 \mathrm{~h})$ was higher $(P<0.05)$ while glucose disappearance $(5.9 \pm 0.3$ vs. $7.3 \pm 0.9 \mathrm{mmol} / \mathrm{kg}$ per $6 \mathrm{~h}$ ) and forearm arteriovenous glucose difference $(64 \pm 24$ vs. $231 \pm 62 \mathrm{mmol} / \mathrm{dl}$ per $6 \mathrm{~h})$ were lower $(P<0.05)$ during the variable than basal infusion. The greater hepatic response during the variable cortisol infusion was mediated (at least in part) by inhibition of insulin and stimulation of glucagon secretion as reflected by lower $(P<$ 0.05) C-peptide (0.29 \pm 0.01 vs. $0.38 \pm 0.04 \mathrm{mmol} /$ liter per $6 \mathrm{~h})$ and higher $(P<0.05)$ glucagon $(42.7 \pm 2.0$ vs. $39.3 \pm 1.8 \mathrm{ng} / \mathrm{ml}$ per $6 \mathrm{~h}$ ) concentrations. In contrast, the decreased rates of glucose uptake appeared to result from a state of "physiologic" insulin resistance. The variable cortisol infusion also increased $(P<0.05)$ postprandial palmitate appearance as well as palmitate, $\beta$-hydroxybutyrate, and alanine concentrations, suggesting stimulation of lipolysis, ketogenesis, and proteolysis. We conclude that the circadian variation in cortisol concentration is of physiologic significance in normal humans. (J. Clin. Invest. 1993. 91:2283-2290.) Key words: glucose metabolism • hydrocortisone $\bullet$ insulin resistance $\bullet$ metyrapone
\end{abstract}

\section{Introduction}

Glucocorticoids are potent regulators of carbohydrate, fat, and protein metabolism $(1,2)$. Glucocorticoid deficiency is associated with increased insulin sensitivity and glucocorticoid excess is associated with insulin resistance (3-6). Elevation of cortisol in the range of $30-40 \mu \mathrm{g} / \mathrm{dl}$ for $12-24 \mathrm{~h}$ enhances lipolysis (7) and proteolysis ( 8 ) as well as impairs both insulin-induced suppression of hepatic glucose release and stimulation of glucose uptake $(5,6)$. Although cortisol concentrations of this magnitude may mimic those present during chronic stress or illness, they are higher and more sustained than those observed

This study was presented in part at the national meeting of the American Diabetes Association, San Antonio, TX, June 21-23, 1992.

Address reprint requests to Dr. Robert A. Rizza, Endocrine Research Unit, Mayo Clinic, 5-164 West Joseph, Rochester, MN 55905.

Received for publication 30 March 1993 and in revised form 21 June 1993.

J. Clin. Invest.

(C) The American Society for Clinical Investigation, Inc.

$0021-9738 / 93 / 11 / 2283 / 08 \$ 2.00$

Volume 92, November 1993, 2283-2290 in healthy individuals under conditions of daily living (9-12). In nonstressed humans, cortisol concentrations rarely exceed $\sim 15-20 \mu \mathrm{g} / \mathrm{dl}$ with such elevations persisting for only a few hours (9-12). The most marked increase in cortisol in healthy subjects generally occurs from the middle of the night to breakfast time with similar but less consistent increases also being observed after food ingestion (11). It is currently unknown whether these variations in cortisol are of physiologic significance in normal humans.

To address this question, we examined the effects of inhibition of the normal nocturnal rise in cortisol on the disposition of a mixed meal. Results were compared to those observed in control experiments in which the normal nocturnal rise in cortisol was reproduced by means of a variable hydrocortisone infusion. In each instance, endogenous cortisol secretion was inhibited by administering metyrapone throughout the night. We specifically studied postprandial carbohydrate metabolism since we anticipated that the effects of the nocturnal rise in cortisol would be more evident in the presence of the complex metabolic milieu that occurs after food ingestion. We tested the hypothesis that the normal nocturnal rise in cortisol would result in metabolic responses that are typically associated with impaired insulin action (e.g., higher glucose concentrations, decreased rates of glucose uptake, and higher rates of hepatic glucose release and free fatty acid appearance). In addition, since hyperglycemia per se is an important determinant of the rates of glucose production and utilization, we also performed control experiments in which the postprandial glucose concentrations that were observed in the absence of the nocturnal rise were matched to those observed in the presence of the nocturnal rise in cortisol. These latter studies permitted us to differentiate the direct effects of cortisol from those due to compensatory increases in glucose concentration.

\section{Methods}

Subjects. After approval by the Mayo Institutional Review Board, 10 healthy volunteers gave written informed consent to participate in the study. The group consisted of five males and five females of mean age $34 \pm 4 \mathrm{yr}$ and mean body mass index $22.7 \pm 0.8 \mathrm{~kg} / \mathrm{m}^{2}$. None of the volunteers was on any medications or had a family history of diabetes mellitus. Subjects were studied in random order on two occasions with experiments being separated by at least $2 \mathrm{wk}$.

Protocol. Volunteers were admitted to the Clinical Research Center at 1700 on the evening before the study. At 1730 a standard meal (636 kcal; $48 \%$ carbohydrate, $32 \%$ fat, $19 \%$ protein) was consumed after which volunteers were fasting until the test meal which was given at 1000 the next morning. An 18-gauge cannula was inserted into a vein of each forearm on the evening of admission. One was used for overnight blood sampling while the other was connected to a multiport infusion set (Burron Medical Inc., Bethlehem, PA) and used for hormone and tracer infusions.

An intravenous infusion of hydrocortisone sodium succinate was commenced at 0100 on the morning after admission. On one occasion this was infused at a constant rate of $0.3 \mu \mathrm{g} / \mathrm{kg}$ per min throughout the 
study while on the other occasion the rate was adjusted every $3 \mathrm{~h}$ in an effort to mimic the normal nocturnal rise in cortisol $(0.3 \mu \mathrm{g} / \mathrm{kg}$ per min from 0100 to $0400,1.0 \mu \mathrm{g} / \mathrm{kg}$ per min from 0400 to $0700,1.4 \mu \mathrm{g} / \mathrm{kg} /$ $\min$ from 0700 to $1000,1.0 \mu \mathrm{g} / \mathrm{kg}$ per min from 1000 to 1300 , and 0.3 $\mu \mathrm{g} / \mathrm{kg}$ per min from 1300 to 1600 ). The order of study was random. On each occasion $2 \mathrm{~g}$ of metyrapone was given by mouth $(0.5 \mathrm{~g}$ every 4 h) to block endogenous cortisol production as described by DeFeo et al. (13).

At 0645 the next morning, the overnight sampling cannula was removed and a retrograde cannula was inserted in an ipsilateral antecubital vein to enable deep venous blood sampling. At the same time an additional 18-gauge cannula was inserted retrogradely in a contralateral hand vein. The hand was placed in a plexiglass box heated to $55-60^{\circ} \mathrm{C}$ in order to permit sampling of arterialized venous blood.

At 0700 a primed $(\sim 14 \mu \mathrm{Ci})$, continuous $(\sim 0.14 \mu \mathrm{Ci} / \mathrm{min})$ infusion of $\left[6-{ }^{3} \mathrm{H}\right]$ glucose was started to enable determination of rates of glucose appearance and disappearance. A primed $(\sim 110 \mu \mathrm{Ci})$ continuous $(\sim 1.1 \mu \mathrm{Ci} / \mathrm{min})$ infusion of $\mathrm{NaH}^{14} \mathrm{CO}_{3}$ was also started at 0700 to enable measurement of the rate of incorporation of carbon dioxide into glucose. In 5 of the 10 volunteers a nonprimed infusion of $\left[9,10-{ }^{3} \mathrm{H}\right]-$ palmitate $(0.3 \mu \mathrm{Ci} / \mathrm{min})$ was started at 0900 to trace free fatty acid kinetics. At 1000, having allowed sufficient time for isotopic equilibration, volunteers ingested a solid mixed $(472 \mathrm{kcal} ; 45 \%$ carbohydrate, $40 \%$ fat and $15 \%$ protein) meal containing $100 \mu \mathrm{Ci}$ of $\left[2-{ }^{3} \mathrm{H}\right]$ glucose and a caffeine-free beverage as previously described (14). At the same time the volunteers also drank $100 \mathrm{ml}$ of water containing $10 \mathrm{~g}$ of D-xylose to permit estimation of carbohydrate absorption.

Blood was sampled at 0100 before starting the cortisol infusion and at two hour intervals from 0200 to 0600 . Arterialized and deep venous samples were drawn simultaneously at 30 , and 0 min before meal ingestion and again at 30,60,90,120,180,240,300, and 360 min after the test meal. Additional arterialized specimens for measurement of specific activity were drawn at 20 and $10 \mathrm{~min}$ before meal ingestion. Blood samples were placed on ice, centrifuged at $4^{\circ} \mathrm{C}$, and stored at $-20^{\circ} \mathrm{C}$. Breath was collected into $2 \mathrm{ml}$ of $0.5 \mathrm{M}$ hyamine (Packard Instrument Co., Inc., Downer's Grove, IL) for measurement of ${ }^{14} \mathrm{CO}_{2}$ specific activity (15). Forearm blood flow was measured using an electrocapacitance plethysmography cuff (UFI, Morro Bay, CA) as previously described (16).

Six of the original 10 volunteers underwent a third study in which hydrocortisone again was infused at a constant rate $(0.3 \mu \mathrm{g} / \mathrm{kg}$ per min) throughout the night. However, after ingestion of the identical test meal, sufficient glucose was infused intravenously to match glucose to the concentrations observed in the same individual when the hydrocortisone infusion rate was varied during the night. Since hyperglycemia appears to have minimal if any direct effect on lipolysis (17), tritiated palmitate was not infused during the third study. In one of these third studies it was not possible for technical reasons to cannulate the forearm deep vein, and in another study an electrical fault led to loss of the isotopic data. Therefore complete forearm and isotopic data were available on only five volunteers.

Analysis. Glucose and lactate were measured using glucose and lactate oxidase methods (Yellow Springs Instruments, Inc., Yellow Springs, $\mathrm{OH}$ ). Plasma insulin, $C$-peptide, and glucagon were measured by radioimmunoassay as previously described (18-20). Cortisol and growth hormone were measured using commercially available kits (Ciba Corning, Norwood, MA; and ICN Biomedicals, Costa Mesa, CA, respectively). Alanine and $\beta$-hydroxybutyrate $(\beta-\mathrm{OHB})^{1}$ were measured using microfluorometric methods $(21,22)$ and $D$-xylose by a colorimetric method $(23) .\left[6-{ }^{3} \mathrm{H}\right]-$ and $\left[2-{ }^{3} \mathrm{H}\right]$ glucose specific activities were determined by a selective enzymatic detritiation of $\left[2-{ }^{3} \mathrm{H}\right]-$ glucose using a modification of the method of Issekutz (24) as previously described (25). Plasma palmitate concentration and specific activity were measured by high-performance liquid chromatography (26) using $\left[{ }^{2} \mathrm{H}_{31}\right]$ palmitate as an internal standard (27).

1. Abbreviation used in this paper: $\beta$-OHB, $\beta$-hydroxybutyrate.
Calculations. Glucose turnover was calculated using Steele's nonsteady state equations (28) as modified by DeBodo et al. (3) in which the pool correction factor was assumed to equal 0.65 and the volume of distribution of glucose to equal $200 \mathrm{ml} / \mathrm{kg}$. The total rate of appearance of unlabeled glucose was measured using $\left[6-{ }^{3} \mathrm{H}\right]$ glucose as the systemic tracer. The rate of appearance of the $\left[2-{ }^{3} \mathrm{H}\right]$ glucose contained in the meal also was traced using $\left[6-{ }^{3} \mathrm{H}\right]$ glucose as previously described (16). The percent of glucose derived from $\mathrm{CO}_{2}$ was calculated by multiplying by 100 the ratio of the specific activity of $\left[{ }^{14} \mathrm{C}\right]$ glucose (product) to the specific activity of breath $\left[{ }^{14} \mathrm{CO}_{2}\right]$ (precursor) (14). Hepatic glucose release was calculated by subtracting the systemic rate of appearance of the ingested glucose (and when appropriate, the glucose infusion rate) from the total systemic rate of appearance. Palmitate appearance was calculated using Steele's nonsteady state equations with a volume of distribution of $90 \mathrm{ml} / \mathrm{kg}(29)$.

Since blood flow did not differ between the basal and variable cortisol studies ( $3.5 \pm 0.5$ vs. $2.9 \pm 0.3 \mathrm{ml} / \mathrm{dl}$ forearm per minute, $P=0.22$ ) and since the variation in blood flow introduced considerable noise into the measurement of forearm glucose uptake, we have elected to present the forearm data as the arteriovenous differences.

Statistical analysis. Data in text and figures are expressed as mean \pm standard error of the mean. Postprandial response, defined as the total area above zero after meal ingestion, was calculated using the trapezoidal rule. Student's one-sided paired $t$ test was used to test the hypotheses that glucose concentration and production rates would be higher and glucose uptake would be lower in the presence than in the absence of the variable cortisol infusion. A two-sided paired $t$ test was used to test all other hypotheses relating to substrate and hormone concentrations. A value of $P<0.05$ was taken to indicate statistical significance.

\section{Results}

Plasma cortisol and glucose concentrations. The variable hydrocortisone infusion resulted in an increase in cortisol concentrations from $\sim 2 \pm 1 \mu \mathrm{g} / \mathrm{dl}$ at 0100 to a peak of $\sim 20 \pm 1$ $\mu \mathrm{g} / \mathrm{dl}$ at 0930 falling to $\sim 9 \pm 1 \mu \mathrm{g} / \mathrm{dl}$ by study end (Fig. 1). In contrast, the two basal hydrocortisone infusions resulted in an increase in cortisol from $\sim 3 \pm 1 \mu \mathrm{g} / \mathrm{dl}$ at 0100 to values of $\sim 10 \mu \mathrm{g} / \mathrm{dl}$ from 1000 to 1200 .

As shown in Fig. 1, fasting glucose concentrations were higher $(P<0.005)$ during the variable than during the basal cortisol infusion $(95 \pm 2$ vs. $88 \pm 2 \mathrm{mg} / \mathrm{dl})$. Upon meal ingestion, total postprandial response $(8.2 \pm 1.0$ vs. $5.1 \pm 0.9 \mathrm{~g} / \mathrm{dl}$ per $6 \mathrm{~h}$ ), peak glucose concentrations ( $182 \pm 5 \mathrm{vs} .158 \pm 7 \mathrm{mg} / \mathrm{dl}$ ), and postprandial glucose nadir $(90 \pm 2$ vs. $77 \pm 4 \mathrm{mg} / \mathrm{dl})$ also were higher $(P<0.01)$ during the variable than during the basal cortisol infusion. Postprandial glucose concentrations were matched in the basal cortisol plus glucose study to those observed in the same individual during the variable cortisol infusion. This required a supplemental intravenous infusion of $464 \pm 127 \mathrm{mg} / \mathrm{kg}$ per $6 \mathrm{~h}$ of glucose.

Plasma insulin, C-peptide, glucagon, and growth hormone concentrations. Although premeal insulin concentrations did not differ amongst studies, the postprandial insulin response was slightly greater $(P<0.05)$ during the variable than during the basal cortisol infusion (Fig. 2). When postprandial glucose concentrations were matched, the insulin response did not differ during the variable and basal cortisol plus glucose infusions (Fig. 2). The C-peptide response to meal ingestion was similar $(0.30 \pm 0.02$ vs. $0.28 \pm 0.02 \mathrm{mmol} /$ liter per $6 \mathrm{~h})$ during the variable and basal cortisol infusions when glucose concentrations were allowed to vary. In contrast, when postprandial glucose concentrations were matched, C-peptide levels were 




Figure 1. Plasma cortisol and glucose concentrations during the variable cortisol infusion (variable cortisol, $n=6$ ) and the basal cortisol infusions with (basal + glucose, $n=6$ ) and without (basal cortisol, $n$ $=10$ ) matched glucose concentrations. A mixed meal was ingested at 1000 .

higher $(P<0.05)$ during the variable than basal cortisol plus glucose infusions.

The postprandial glucagon concentrations were similar during the variable and basal cortisol infusions $(41.1 \pm 1.9$ vs. $41.8 \pm 2.5 \mathrm{ng} / \mathrm{ml}$ per $6 \mathrm{~h}$ ) when glucose concentrations were allowed to vary. On the other hand when glucose concentrations were matched, glucagon concentrations were higher $(P$ $<0.05$ ) during the variable than basal cortisol plus glucose infusions. Overnight and postprandial growth hormone concentrations did not differ between studies (data not shown). Taken together these data indicate an inhibitory effect of the variable cortisol infusion on insulin secretion and a stimulatory effect on glucagon secretion.

Rates of glucose appearance and disappearance, carbon dioxide incorporation into glucose, and plasma D-xylose concentrations. For the plasma glucose concentration to rise there must (by definition) be more glucose entering than leaving the circulation. Since the initial postprandial rise in plasma glucose was greater during the variable than the basal cortisol infusion, it follows that the difference between glucose appearance and glucose disappearance must have been greater during the former than the latter $(330 \pm 44$ vs. $209 \pm 51 \mu \mathrm{mol} / \mathrm{kg}$ per $2 \mathrm{~h} ; P$ $<0.02$ ). However when the individual components of glucose appearance were compared, there was no detectable difference in the appearance of ingested glucose, hepatic glucose release or carbon dioxide incorporation into glucose during the variable and basal cortisol infusions (Fig. 3). There also was no detectable difference in either glucose disappearance, or the arteriovenous difference of glucose across the forearm between studies (Fig. 4).
Since hyperglycemia stimulates glucose uptake and inhibits glycogenolysis and gluconeogenesis (30-33), it is possible that these similar rates of glucose turnover represent offsetting effects of cortisol and hyperglycemia. When glucose concentrations were matched, hepatic glucose release $(2.6 \pm 0.2$ vs. $1.5 \pm 0.4 \mathrm{nmol} / \mathrm{kg}$ per $6 \mathrm{~h}$ ) and carbon dioxide incorporation into glucose were higher $(P<0.05$; Fig. 3$)$ whereas glucose disappearance $(5.9 \pm 0.3$ vs. $7.3 \pm 0.9 \mathrm{mmol} / \mathrm{kg}$ per $6 \mathrm{~h})$ and forearm arteriovenous difference $(64 \pm 24 \mathrm{vs} .231 \pm 62 \mathrm{mmol} / \mathrm{dl}$ per $6 \mathrm{~h})$ were lower $(P<0.05$; Fig. 4$)$ during the variable than basal cortisol plus glucose study. The systemic rate of appearance of ingested glucose was slightly but not significantly greater during the variable than the basal plus glucose study (Fig. 3). Plasma D-xylose concentration, a marker of carbohydrate absorption, did not differ amongst studies (data not shown).

Lactate, alanine, and $\beta-O H B$ concentrations. Lactate and alanine concentration increased and $\beta$-OHB concentrations decreased after meal ingestion. The magnitude of the change in lactate concentration did not differ amongst studies (Fig. 5). However when glucose concentrations were matched, both plasma alanine $(126 \pm 9$ vs. $101 \pm 6 \mathrm{~mol} /$ liter per $6 \mathrm{~h})$ and $\beta$ OHB ( $30 \pm 4$ vs. $6 \pm 1 \mathrm{mmol} /$ liter per $6 \mathrm{~h}$ ) concentrations were higher $(P<0.05)$ during the variable than during the basal cortisol plus glucose study (Fig. 5).

Palmitate concentration and palmitate appearance. Premeal palmitate concentrations ( $134 \pm 23$ vs. $114 \pm 23 \mu \mathrm{mol} /$ liter ) and palmitate appearance ( $2.3 \pm 0.4$ vs. $2.2 \pm 0.5 \mu \mathrm{mol} / \mathrm{kg}$ per min $)$ did not differ $(P=0.4-0.8)$ during the variable and basal cortisol infusions (Fig. 6). In contrast, postprandial pal-
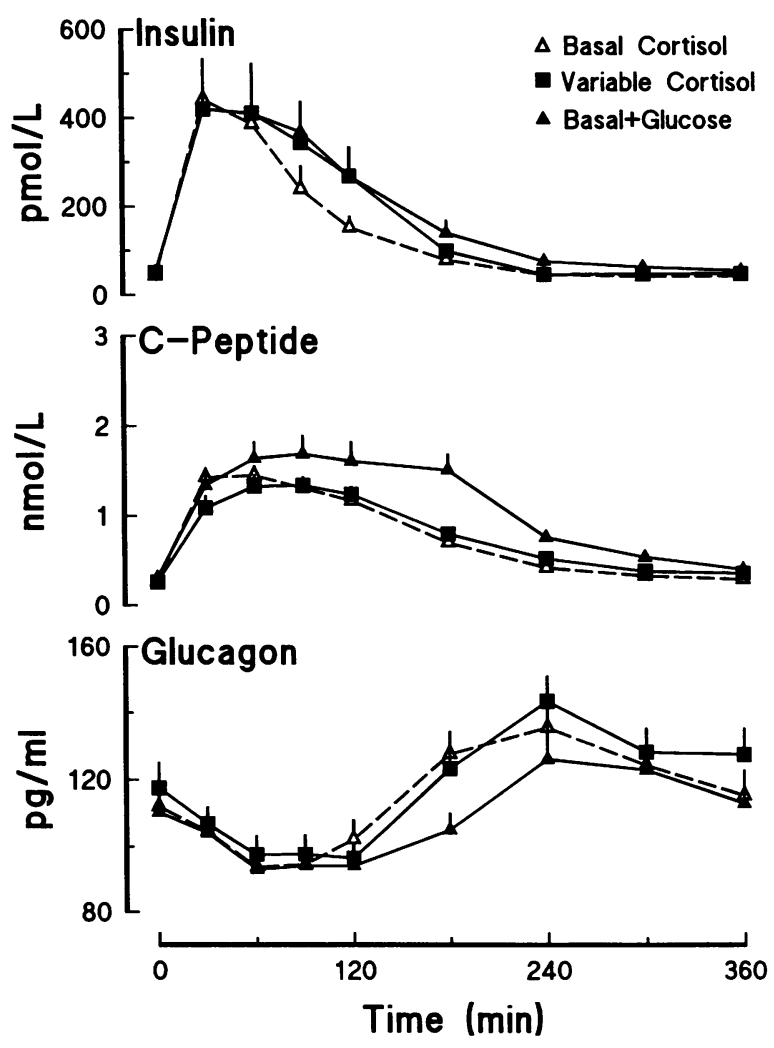

Figure 2. Plasma concentrations of insulin, C-peptide, and glucagon during the variable cortisol infusion and the basal cortisol infusions with and without matched glucose concentrations. A mixed meal was ingested at time zero. Symbols as in Fig. 1. L, liter. 

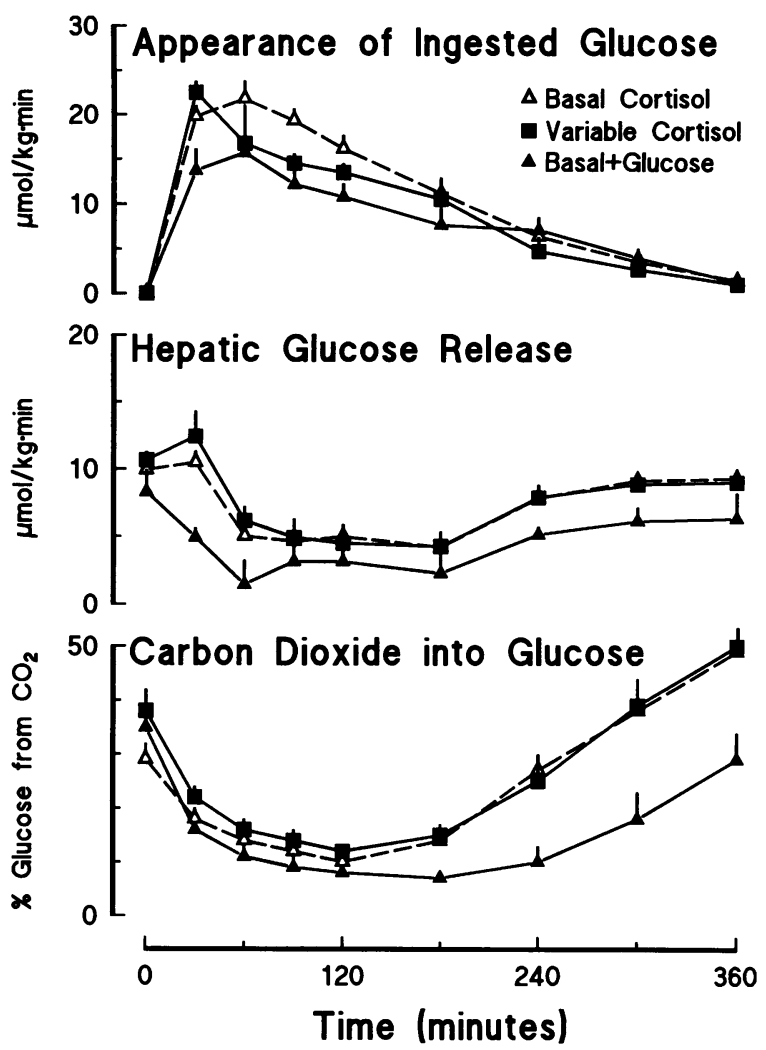

Figure 3. Rates of appearance of ingested glucose, hepatic glucose release, and carbon dioxide incorporation into glucose during the variable cortisol infusion and the basal cortisol infusions with and without matched glucose concentrations. A mixed meal was ingested at time zero. Symbols as in Fig. 1.

mitate concentrations ( $38 \pm 5 \mathrm{vs.} 29 \pm 5 \mathrm{mmol} /$ liter per $6 \mathrm{~h}$ ) and rates of appearance $(570 \pm 76$ vs. $496 \pm 73 \mu \mathrm{mol} / \mathrm{kg}$ per $6 \mathrm{~h})$ were both higher $(P<0.05)$ during the variable than during the basal cortisol infusion.

\section{Discussion}

Many previous studies have established that cortisol is a potent counterregulatory hormone (1-6). Cortisol in concentrations similar to those encountered during hypoglycemia, stress, or serious illness $(34,35)$ has powerful effects on carbohydrate, fat, and protein metabolism $(2,5,7,8,36)$. The present studies extend these observations by demonstrating that cortisol, in concentrations that mimic those normally present in healthy humans during sleep, increased both fasting and postprandial glucose concentrations. Cortisol increased glucose concentration by stimulating hepatic glucose output and by inhibiting muscle glucose uptake. The greater incorporation of ${ }^{14} \mathrm{CO}_{2}$ into glucose suggests that accelerated gluconeogenesis contributed to the increase in glucose output. The concomitant increase in plasma alanine and $\beta$-OHB concentrations suggests enhanced proteolysis and ketogenesis whereas the increase in palmitate concentration and appearance indicates enhanced adipose tissue lipolysis. The hepatic effects of cortisol appeared to be mediated (at least in part) by inhibition of insulin and stimulation of glucagon secretion whereas the extrahepatic effects appeared to be due to the induction of a state of "physiologic" insulin resistance. With the exception of palmitate appearance, all of these responses were offset by a compensatory increase in

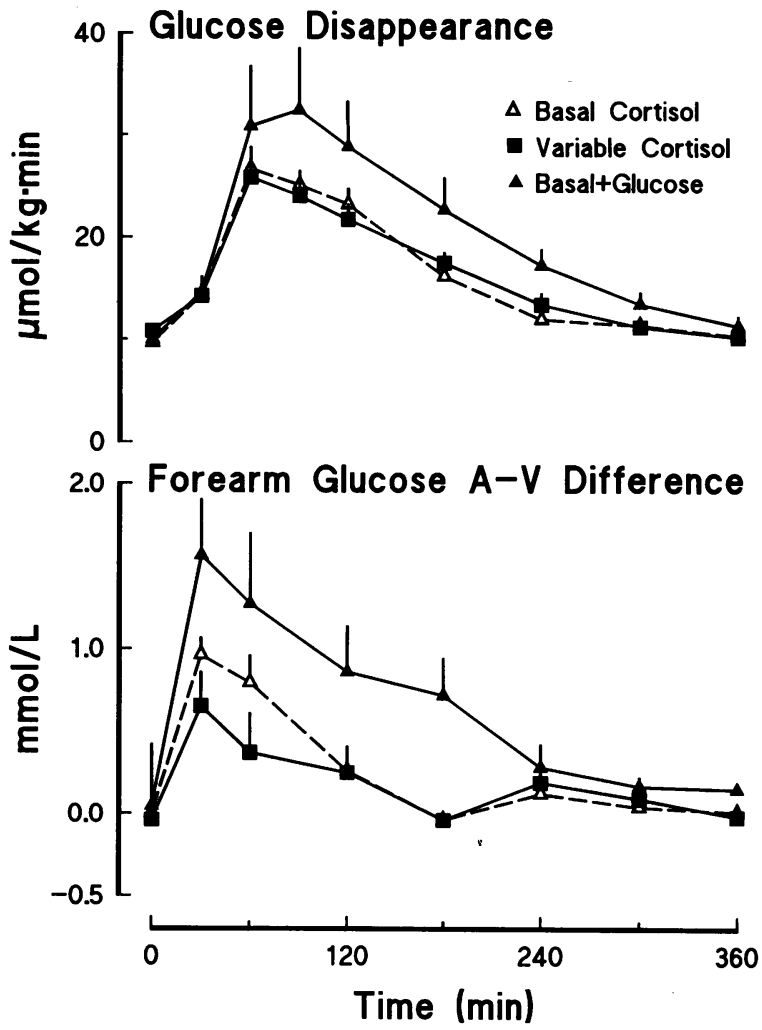

Figure 4. Rates of glucose disappearance (measured isotopically) and forearm glucose arteriovenous $(A-V)$ difference during the variable cortisol infusion and the basal cortisol infusions with and without matched glucose concentrations. A mixed meal was ingested at time zero. Symbols as in Fig. 1. L, liter.
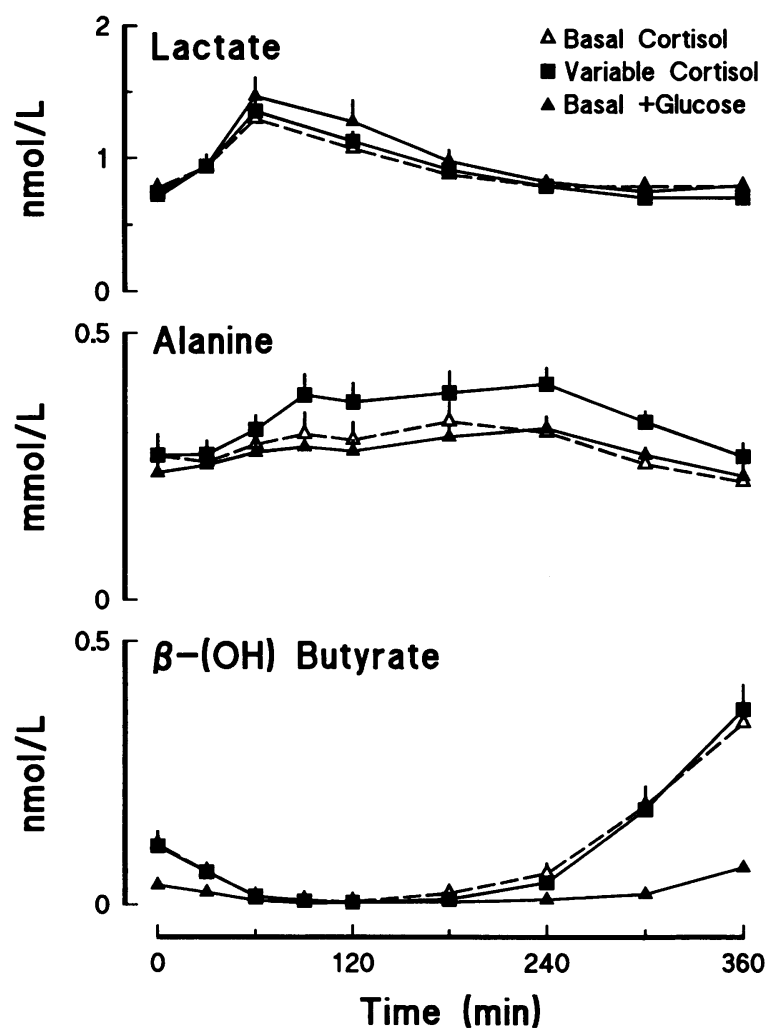

Figure 5. Levels of lactate, alanine, and $\beta$-hydroxybutyrate during the variable cortisol infusion and the basal cortisol infusions with and without matched glucose concentrations. A mixed meal was ingested at time zero. Symbols as in Fig. 1. L, liter. 



Figure 6. Palmitate concentration and appearance during the variable cortisol $(n=5)$ and the basal cortisol $(n=5)$ infusions. A mixed meal was ingested at time zero. $\mathrm{L}$, liter.

plasma glucose concentration. Thus our data suggest that the nocturnal rise in cortisol is important in the regulation of postprandial carbohydrate metabolism in normal humans.

The paradigm used in the present study consisted of inhibiting endogenous cortisol secretion with metyrapone while infusing hydrocortisone either at a constant rate or in a manner that mimicked the well-described nocturnal increase in cortisol. Previous studies by DeFeo et al. (13) have demonstrated that metyrapone has no intrinsic effects on carbohydrate metabolism as long as cortisol is replaced. The variable cortisol infusion used in the present experiments resulted in a gradual increase in cortisol over $6 \mathrm{~h}$ to a peak concentration of $\sim 20$ $\mu \mathrm{g} / \mathrm{dl}$ followed by a return to basal values over the succeeding 6 h. Although the peak concentration is slightly higher than that reported in most previous studies characterizing nocturnal cortisol secretion in nonstressed humans $(\sim 15-18 \mu \mathrm{g} / \mathrm{dl})$, the temporal pattern of change is quite similar (9-12). On the other hand, the basal infusion was accompanied by a slight but consistent increase in cortisol to $\sim 9 \mu \mathrm{g} / \mathrm{dl}$. Since the reported

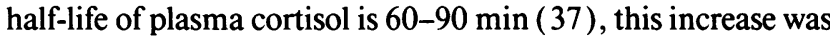
likely due to the time required to reach steady state (i.e., four to five half-lives). Therefore while the slightly higher peak may have led to an overestimate of the metabolic effects of cortisol, this was likely counterbalanced by the increase in cortisol during the basal infusion which presumably would lead to an underestimate of the importance of the nocturnal rise in cortisol.

The present studies indicate that the nocturnal rise in cortisol reduces postprandial glucose uptake whether measured isotopically or as the arteriovenous difference across the forearm. Cortisol appears to do so by impairing insulin action as evidenced by lower rates of glucose uptake in the presence of identical glucose and insulin concentrations (Fig. 4). The decrease in extraction of glucose across the forearm implies that skeletal muscle participates in this response. The observation that physiologic increases in cortisol can antagonize insulin action is consistent with earlier studies which have examined the effects of higher or more prolonged elevations of cortisol (4-6). The mechanism by which physiologic changes in cortisol regulate glucose uptake is not known. Although in vitro studies indicate that cortisol can decrease glucose uptake in both muscle and adipocytes, it does not seem to do so by altering the number of glucose transporters or insulin receptors $(4,38-41)$. On the other hand the hyperinsulinemia that accompanies glucocorticoid excess in vivo may influence both processes (41). Since overnight insulin concentrations did not differ during the variable and basal cortisol infusions, it is unlikely that hyperinsulinemia had important metabolic effects in the present experiments.

Previous studies have suggested that cortisol can decrease glucose uptake by increasing free fatty acid availability (42). While palmitate concentrations were higher during the variable than during the basal cortisol infusion, the differences were minimal. Furthermore, postprandial suppression of lipolysis as reflected by the decrement in palmitate appearance was not impaired. Therefore free fatty acid concentrations were falling in both groups at the time when differences in glucose disposal were most marked. This argues against a major role for changes in circulating fatty acid concentration mediating the effect of cortisol on glucose uptake. Our data do not exclude the possibility that cortisol decreased forearm glucose uptake by increasing intramuscular oxidation of fat, amino acids ( 43 , $44)$, and/or ketone bodies $(45,46)$. However, we believe the latter two to be less likely. Regardless of the cellular mechanism, our data indicate that a relatively brief elevation of cortisol (i.e., $\sim 6 \mathrm{~h}$ ) can result in a substantial change in insulin action in both muscle and adipose tissue.

The present data also suggest that physiologic changes in cortisol can alter the hepatic response to food ingestion. Both postprandial hepatic glucose release and the rate of incorporation of ${ }^{14} \mathrm{CO}_{2}$ into glucose (a qualitative indicator of gluconeogenesis) were increased by the nocturnal rise in cortisol. Enhanced hepatic glucose release during the nocturnal rise in cortisol is consistent with what would be predicted from previous experiments using supraphysiologic concentrations of cortisol (5-8). Cortisol could have increased hepatic glucose production by at least three mechanisms. First, cortisol could increase the concentration as well as the activity of enzymes in the gluconeogenic and glycogenolytic pathways $(1,2)$. If such effects occurred in the present experiments, the relatively short lag time from the initial increase in cortisol to detectable changes in hepatic glucose release would seem to favor a change in enzyme activity rather than a change in enzyme mass. Second, cortisol-induced stimulation of lipolysis could increase gluconeogenesis by increasing the intrahepatic redox potential as well as by increasing the supply of glycerol $(7,42)$. Gluconeogenesis could also be enhanced by increased plasma alanine availability (8). Our data showing increased palmitate flux and increased alanine concentrations are consistent with these possibilities.

Third, and perhaps most importantly, the nocturnal rise in cortisol could alter pancreatic alpha and beta cell function. In vitro studies have demonstrated that very high cortisol concentrations can inhibit insulin synthesis and secretion (47-49). In addition, people treated with high doses of prednisone for several days have elevated fasting glucagon concentrations as well 
as enhanced responses to intravenous arginine (50). While these studies indicate that very high concentrations of glucocorticoids can inhibit insulin and stimulate glucagon secretion, somewhat surprisingly the present data indicate that physiologic concentrations do so as well. Thus despite comparable glucose concentrations, C-peptide concentrations were lower and glucagon concentrations were higher during the variable than the basal plus glucose study (Fig. 2). Assuming that Cpeptide and glucagon clearance remained constant on the two study days these data taken together indicate that insulin secretion was lower and glucagon secretion higher during the variable cortisol infusion. Therefore the resultant increase in the portal venous glucagon/insulin ratio potentially could account for much if not all of the associated increase in hepatic glucose release, gluconeogenesis, and $\beta$-OHB concentration. In addition, the inhibitory effect of cortisol on insulin secretion would explain the absence of peripheral hyperinsulinemia despite a state of insulin resistance. Presumably during long-term glucocorticoid excess this inhibitory effect is offset by chronic hyperglycemia (41).

In addition to reducing its own endogenous production of glucose, the liver also contributes to postprandial carbohydrate tolerance by extracting a portion of the ingested glucose as it travels from the gut to the systemic circulation (51). It is presumed that most of the extracted glucose is eventually stored as glycogen via either the direct or indirect pathways. Glucocorticoid excess can increase glycogen synthesis in the fasting state $(1,2)$. We are not aware of any previous studies examining the impact of cortisol on liver glycogen synthesis in the fed state. While the systemic rate of appearance of ingested glucose tended to be higher (and therefore initial splanchnic extraction lower) during the variable than during the basal cortisol plus glucose infusion, this difference did not reach statistical significance. The lack of difference did not appear to be due to offsetting changes in gut absorption since D-xylose concentrations were virtually identical during the variable and basal cortisol infusions. The lack of a detectable effect on the systemic appearance of ingested glucose suggests that physiologic changes in cortisol have minimal impact on either absorption of a mixed meal or on splanchnic uptake of glucose. This is not particularly surprising, since the portal to peripheral glucose gradient appears to have a greater effect on hepatic glucose uptake than does the portal insulin concentration $(52,53)$. One would therefore anticipate that a hormone whose primary role is to antagonize insulin action would not impact on this process.

As with all studies, the present experiments have several potential limitations. As previously discussed in detail (14, 54, 55 ), measurement of the rate of incorporation of ${ }^{14} \mathrm{CO}_{2}$ into glucose only provides an index of gluconeogenesis since the intramitochondrial specific activity is not known. Dilution of labeled precursors within the oxaloacetate pool will result in an underestimate of gluconeogenesis. However, since it is likely that lipolysis and proteolysis if anything were greater during the variable than basal cortisol infusion, this would result in a conservative error since we observed higher rates of gluconeogenesis with the variable cortisol study. With regard to our measures of proteolysis and lipolysis, a change in alanine concentration could be due to a change in de novo alanine synthesis from pyruvate, a decrease in alanine utilization and/or release during proteolysis (56). The comparable plasma lactate concentrations and rates of lactate release from the forearm during the variable and basal cortisol infusions argue against substantial differences in de novo synthesis from pyruvate. In theory, palmitate appearance may only provide a qualitative estimate of lipolysis. If degradation to mono- or diglycerides is followed by reesterification this will result in release of free fatty acids into the circulation in the absence of net lipolysis (27). However, since the ratio of FFA/glycerol appearance has been shown to be close to 3:1 under a variety of circumstances (57-59), this suggests that reesterification is likely to be minimal in humans. Finally, measurement of palmitate appearance will not detect free fatty acids that are oxidized prior to mixing with the systemic circulation (e.g., within muscle or the splanchnic bed). Therefore, although the increase in palmitate appearance indicates that more free fatty acids reached the systemic circulation during the variable than during the basal cortisol infusion, it does not necessarily reflect the true rate of lipolysis in all tissue compartments.

The observation that glucose tolerance is worse when a meal is eaten later in the day than when the same meal is eaten in the morning is well established $(60,61)$. Recently Van Cauter et al. (62) proposed that this may be due to a decrease in $\beta$ cell responsiveness to glucose in the evening. They noted that meal tolerance and cortisol concentrations were inversely related. This led them to suggest that the relative deficiency of cortisol in the evening led to glucose intolerance. Although our data provide no insight into circadian variation in glucose tolerance, they do argue against a causal role for cortisol in the decrease in evening glucose tolerance. If anything, our observation that the nocturnal rise in cortisol is associated with a decrease in both insulin secretion and action would suggest that the impairment in evening glucose tolerance would have been even greater if cortisol concentrations had not fallen during the day. A second issue relates to the role of cortisol in the so-called "dawn phenomenon." The latter refers to an increase in insulin requirements that generally occurs between 0600 and 0900 in most people with insulin-dependent diabetes mellitus. The cause of this increase in insulin requirement is not known. Some authors have ascribed it to the nocturnal increase in cortisol, (63) although others have reported no effect of blockade of cortisol secretion with metyrapone on morning insulin requirements (64). More recently, the dawn phenomenon has been ascribed to the nocturnal increase in growth hormone (65), although again studies that inhibited nocturnal growth hormone secretion have been conflicting (66). In our study, growth hormone concentrations did not differ in the presence or absence of the nocturnal rise in cortisol. While our experiment was not designed to assess the effects of the nocturnal rise in cortisol on early morning insulin requirements, our data do show that this rise can lead to a degree of "physiologic" insulin resistance. Whether this also occurs in people with diabetes mellitus remains to be established.

In conclusion, the present studies demonstrate that an increase in cortisol concentration of a magnitude similar to that observed in healthy nonstressed humans during sleep can influence glucose metabolism. Postprandial hepatic glucose release was higher and postprandial muscle glucose uptake was lower in the presence than in the absence of a nocturnal rise in cortisol. Under normal circumstances these effects are offset by a compensatory increase in glucose concentration. The hepatic actions of cortisol appeared to be mediated (at least in part) by alterations in the secretion of insulin and glucagon while the extrahepatic actions appeared to be due to the ability of cortisol to create a state of "physiologic" insulin resistance. The corti- 
sol-induced increase in palmitate, $\beta$-OH butyrate and alanine concentrations are consistent with additional effects on lipolysis, ketogenesis, and perhaps proteolysis. These findings suggest that the nocturnal rise in cortisol regulates the complex interplay between tissue response, hormone secretion, and substrate availability that is required for the maintenance of carbohydrate tolerance in normal humans. Whether an altered response to the nocturnal rise in cortisol contributes to the metabolic abnormalities associated with disease states such as diabetes mellitus remains to be determined.

\section{Acknowledgments}

We wish to thank J. Aikens, K. Hammel, J. King, T. Madson, D. Nash, and M. Persson for technical assistance, M. Campion for assistance in preparing the manuscript, and the staff of the General Clinical Research center for assistance in performing the studies.

This work was supported by the National Institutes of Health (DK29953, DK-38092, and RR-00585) and the Mayo Foundation.

\section{References}

1. Long, C., O. Smith, and E. Fry. 1960. Actions of cortisol and related compounds on carbohydrate and protein metabolism. In Metabolic Effects of Adrenal Hormones. W. Wolsterholme, and M. Connor, editors. Churchill, London. 4-24.

2. McMahon, M., J. Gerich, and R. Rizza. 1988. Effects of glucocorticoids on carbohydrate metabolism. Diabetes/Metab. Rev. 4:17-30.

3. DeBodo, R. C., R. Steele, N. Altszuler, A. Dunn, and J. S. Bishop. 1963. On the hormone regulation of carbohydrate metabolism: studies with ${ }^{14} \mathrm{C}$ glucose. Recent Prog. Horm. Res. 19:445-488.

4. Riddick, F., D. Reisler, and D. Kipnis. 1962. The sugar transport system in striated muscle: effect of growth hormone, hydrocortisone, and alloxan diabetes. Diabetes. 11:171-178.

5. Rizza, R., L. Mandarino, and J. Gerich. 1982. Cortisol induced insulin resistance in man: impaired suppression of glucose production and stimulation of glucose utilization due to a post-receptor defect of insulin action. J. Clin. Endocrinol. Metab. 54:131-138.

6. Nosadini, R., S. DelPrato, A. Tiengo, A. Valerio, M. Muggeo, G. Opocher, F. Mantero, E. Dumer, C. Marescotti, F. Mollo, and F. Belloni. 1983. Insulin resistance in Cushing's disease. J. Clin. Endocrinol. Metab. 57:529-536.

7. Divertie, G. D., M. D. Jensen, and J. M. Miles. 1991. Stimulation of lipolysis in humans by physiological hypercortisolemia. Diabetes. 40:1228-1232.

8. Simmons, P. S., J. M. Miles, J. E. Gerich, and M. W. Haymond. 1984. Increased proteolysis: an effect of increases in plasma cortisol within the physiologic range. J. Clin. Invest. 73:412-420.

9. Weitzman, E. D., D. Fukushima, C. Nogeire, H. Roffwarg, T. F. Gallagher, and L. Hellman. 1970. Twenty-four hour pattern of the episodic secretion of cortisol in normal subjects. J. Clin. Endocrinol. 33:14-22.

10. Clore, J. N., S. T. Helm, J. E. Nestler, and W. G. Blackard. 1990. Impaired modulation of hepatic glucose output overnight after a 72 -h fast in normal man. J. Clin. Endocrinol. Metab. 70:865-868.

11. Van Cauter, E., J. D. Blackman, D. Roland, J-P. Spire, S. Refetoff, and K. S. Polonsky. 1991. Modulation of glucose regulation and insulin secretion by circadian rhythmicity and sleep. J. Clin. Invest. 88:934-942.

12. Nielsen, H. K., K. Brixen, M. Kassem, P. Charles, and L. Mosekilde. 1992. Inhibition of the morning cortisol peak abolishes the expected morning decrease in serum osteocalcin in normal males: evidence of a controlling effect of serum cortisol on the circadian rhythm in serum osteocalcin. J. Clin. Endocrinol. Metab. 74:1410-1414.

13. DeFeo, P., G. Perriello, M. M. Ventura, P. Brunetti, F. Santeusanio, J. E. Gerich, and G. B. Bolli. 1987. The pancreatic-adrenocortical-pituitary clamp technique for study of counterregulation in humans. Am. J. Physiol. 252:E565E570.

14. McMahon, M., H. M. Marsh, and R. A. Rizza. 1989. Effects of basal insulin supplementation on disposition of mixed meal in obese patients with NIDDM. Diabetes. 38:291-303.

15. Kaihara, S., and H. Wagner. 1968. Measurement of intestinal fat absorption with carbon-14 labelled tracers. J. Lab. Clin. Med. 71:400-411.

16. Firth, R. G., P. M. Bell, H. M. Marsh, I. Hansen, and R. A. Rizza. 1986. Postprandial hyperglycemia in patients with noninsulin-dependent diabetes mellitus. J. Clin. Invest. 77:1525-1532.

17. Caruso, M., G. D. Divertie, M. D. Jensen, and J. M. Miles. 1990. Lack of effect of hyperglycemia on lipolysis in humans. Am. J. Physiol. 259:E542-E547.
18. Herbert, V., K. Lau, C. Gottlieb, and S. Bleicher. 1965. Coated charcoal immunoassay of insulin. J. Clin. Endocrinol. Metab. 25:1375-1384.

19. Heding, L., and S. Rasmussen. 1975. Human C-peptide in normal and diabetic subjects. Diabetologia. 11:201-206.

20. Faloona, G., and R. Unger. 1974. Glucagon. In Methods of Hormone Radioimmunoassay. B. Jaffe and H. Behrman, editors. Academic Press, Inc., New York. 317-330.

21. Karl, I. E., A. S. Pagliara, and D. M. Kipnis. 1972. A microfluorometric enzyme assay for the determination of alanine and pyruvate in plasma and tissue. J. Lab. Clin. Med. 80:434-441.

22. Cahill, G., M. Herrera, A. Morgan, J. Soeldner, J. Steinke, P. Levy, G. Reichard, and D. Kipnis. 1966. Hormone-fuel interrelationships during fasting. J. Clin. Invest. 45:1751-1769.

23. Eberts, T. J., R. H. Sample, M. R. Glick, and G. H. Ellis. 1979. A simplified, colorimetric micromethod for xylose in serum or urine with phloroglucinol. Clin. Chem. 25:1440-1443.

24. Issekutz, B. 1977. Studies on hepatic glucose cycles in normal and methylprednisone treated dogs. Metab. Clin. Exp. 26:157-170.

25. Bell, P. M., R. G. Firth, and R. A. Rizza. 1986. Assessment of insulin action in insulin-dependent diabetes mellitus using $\left[6{ }^{14} \mathrm{C}\right]$ glucose, $\left[3^{3} \mathrm{H}\right]$ glucose, and $\left[2^{3} \mathrm{H}\right]$ glucose. J. Clin. Invest. 78:1479-1486.

26. Miles, J. M., M. G. Ellman, K. L. McClean, and M. D. Jensen. 1987. Validation of a new method for the determination of free fatty acid turnover. Am. J. Physiol. 252:E431-E438.

27. Jensen, M. D., P. J. Rogers, M. G. Ellman, and J. M. Miles. 1988. Choice of infusion-sampling mode for tracer studies of free fatty acid metabolism. Am. J. Physiol. 254:E562-E565.

28. Steele, R., J. Wall, R. DeBodo, and N. Altszuler. 1956. Measurement of size and turnover rate of body glucose pool by the isotope dilution method. Am. J. Physiol. 187:15-24.

29. Jensen, M. D., V. Heiling, and J. M. Miles. 1990. Measurement of nonsteady state free fatty acid turnover. Am. J. Physiol. 258:E103-E108.

30. Glinsmann, W. H., E. P. Hern, and A. Lynch. 1969. Intrinsic regulation of glucose output by rat liver. Am. J. Physiol. 216:698-703.

31. Ruderman, N. B., and M. G. Herrera. 1968. Glucagon regulation of hepatic gluconeogenesis. Am. J. Physiol. 214:1346-1351.

32. Cherrington, A. D., P. E. Williams, and M. S. Harris. 1976. Relationship between the plasma glucose level and glucose uptake in the conscious dog. Metab. Clin. Exp. 27:787-791.

33. Bergman, R., and R. Bucolo. 1974. Interaction of insulin and glucose in the control of hepatic glucose balance. Am. J. Physiol. 227:1314-1322.

34. Plumpton, F. S., and G. M. Besser. 1969. The adrenocortical response to surgery and insulin induced hypoglycemia in corticosteroid-treated and normal subjects. Br. J. Surg. 56:216-219.

35. Jacobs, H. S., and J. D. M. Nabarro. 1969. Plasma 11-hydroxycorticosteroid and growth hormone levels in acute medical illness. Br. Med. J. 2:595-598.

36. Rizza, R. A., P. E. Cryer, and J. E. Gerich. Role of glucagon, catecholamines, and growth hormone in human glucose counterregulation. J. Clin. Invest. $64: 62-71$.

37. Bradley, E. M., and C. Waterhouse. 1966. Effect of estrogen administration on extravascular cortisol. J. Clin. Endocrinol. Metab. 26:705-714.

38. DePirro, R., A. Green, M. Kao, and J. M. Olefsky. 1981. Effects of prednisone and dexamethasone in vivo and in vitro: studies of insulin binding, deoxyglucose uptake and glucose oxidation in rat adipocytes. Diabetologia. 21:149-153.

39. Knutson, V. P. 1986. The acute and chronic effects of glucocorticoids on insulin receptor and insulin responsiveness. J. Biol. Chem. 261:10306-10312.

40. Haber, R. S., and S. P. Weinstein. 1992. Role of glucose transporters in glucocorticoid-induced insulin resistance. Diabetes. 41:728-735.

41. Fantus, I. G., J. Ryan, N. Hizuka, and P. Gorden. 1981. The effect of glucocorticoids on the insulin receptor: an in vivo and in vitro study. $J$. Clin. Endocrinol. Metab. 52:953-960.

42. Ekstrand, A., C. Saloranta, J. Ahonen, C. Gronhagen-Riska, and L. C. Groop. 1992. Reversal of stroid-induced insulin resistance by a nicotinic-acid derivative in man. Metab. Clin. Exp. 41:692-697.

43. Tessari, P., S. Inchiostro, G. Biolo, E. Duner, R. Nosadini, A. Tiengo, and G. Crepaldi. 1985. Hyperaminoacidemia reduces insulin-mediated glucose disposal in healthy man. Diabetologia. 28:870-872.

44. Pisters, P. W. T., N. P. Restifo, E. Cersosimo, and M. F. Brennan. 1991. The effects of euglycemic hyperinsulinemia and amino acid infusion on regional and whole body glucose disposal in man. Metab. Clin. Exp. 40:59-65.

45. Maizels, E. Z., N. B. Ruderman, M. N., Goodman, and D. Lau. 1977. Effect of acetoacetate on glucose metabolism in the soleus and extensor digitorum longus muscles of the rat. Biochem. J. 162:557-568.

46. Shaw, J. H. F., and R. R. Wolfe. 1984. Influence of $\beta$-hydroxybutyrate infusion on glucose and free fatty acid metabolism in dogs. Am. J. Physiol. 247:E756-764.

47. Philippe, J., E. Giordana, A., Gjinovci, and P. Meda. 1992. Cyclic adenosine monophosphate prevents the glucocorticoid-mediated inhibition of insulin gene expression in rodent islet cells. J. Clin. Invest. 90:2228-2233.

48. Kalhan, S., and P. A. J. Adam. 1975. Inhibitory effect of prednisolone on 
insulin secretion in man: model for duplication of blood glucose concentration. J. Clin. Endocrinol Metab. 41:600-609.

49. Pierluissi, J., F. O. Navas, and S. J. H. Ashcroft. 1986. Effect of adrenal steroids on insulin release from cultured rat islets of Langerhans. Diabetologia. 29:119-121.

50. Marco, J., C. Calle, D. Roman, M. Biaz-Fierros, M. Villanueva, M., and I Valverede. 1973. Hyperglucagonism induced by glucocorticoid treatment in man. N. Engl. J. Med. 288:128-131.

51. Dinneen, S., J. Gerich, and R. Rizza. 1992. Carbohydrate metabolism in non-insulin-dependent diabetes mellitus. N. Engl. J. Med. 327:707-713.

52. Adkins, B. A., S. R. Myers, G. K. Hendrick, R. W. Stevenson, P. E Williams, and A. D. Cherrington. 1987. Importance of the route of intravenous glucose delivery to hepatic glucose balance in the conscious dog. J. Clin. Invest. 79:557-565.

53. DeFronzo, R., E. Ferrannini, R. Hendler, P. Felig, and J. Wahren. 1983. Regulation of splanchnic and peripheral glucose uptake by insulin and hypoglycemia in man. Diabetes. 32:35-45.

54. Katz, J. 1985. Determination of gluconeogenesis in vivo with ${ }^{14} \mathrm{C}$ labeled substrates. Am. J. Physiol. 17:391-399.

55. Brosnan, J. T. 1982. Pathways of carbon flux in gluconeogenesis. Fed. Proc. 41:91-94.

56. Haymond, M. W., and J. M. Miles. 1982. Branched chain amino acids as a major source of alanine nitrogen in man. Diabetes. 31:86-89.

57. Shaw, J., and R. Wolfe. 1987. The integrated effect of adrenergic blockade on glucose, fatty acid, and glycerol kinetics: responses in the basal state and during hormonal control with somatostatin-hormone infusion. J. Surg. Res. 42:257-272.

58. Bougneres, P., I. Karl, L. Hillman, and D. Bier. 1982. Lipid transport in the human newborn: palmitate and glycerol turnover and the contribution of glycerol to neonatal hepatic glucose output. J. Clin. Invest. 70:262-270.

59. Wolfe, R., E. Peters, S. Klein, O. Holland, J. Rosenblatt, and H. Gary. 1987. Effect of short-term fasting on lipolytic responsiveness in normal and obese human subjects. Am. J. Physiol. 252:E189-E196.

60. Bowen, A. J., and R. L. Reeves. 1967. Diurnal variation in glucose tolerance. Arch. Intern. Med. 119:261-264.

61. Service, F. J., L. D. Hall, R. E. Westland, P. C. O'Brien, V. L. W. Go, M. W. Haymond, and R. A. Rizza. 1983. Effects of size, time of day and sequence of meal ingestion on carbohydrate tolerance in normal subjects. Diabetologia. 25:316-321.

62. Van Cauter, E., E. T. Shapiro, H. Tillil, and K. S. Polonsky. 1992. Circadian modulation of glucose and insulin responses to meals: relationship to cortisol rhythm. Am. J. Physiol. 262:E467-E475.

63. Skor, D. A., N. H. White, L. Thomas, S. D. Shah, P. E. Cryer, and J. V. Santiago. 1983. Examination of the role of the pituitary-adrenocortical axis, counterregulatory hormones, and insulin clearance in variable nocturnal insulin requirements in insulin-dependent diabetes. Diabetes. 32:403-407.

64. Bright, G. M., T. W. Melton, A. D. Rogol, and W. L. Clarke. 1980. Failure of cortisol blockade to inhibit early morning increases in basal insulin requirements in fasting insulin-dependent diabetes. Diabetes. 29:662-664.

65. Campbell, P. J., G. B. Bolli, P. E. Cryer, and J. E. Gerich. 1985. Sequence of events during development of the Dawn Phenomenon in insulin-dependent diabetes mellitus. Metab. Clin. Exp. 34:1100-1104.

66. Skor, D. A., N. H. White, L. Thomas, and J. V. Santiago. 1985. Influence of growth hormone on overnight insulin requirements in insulin-dependent diabetes. Diabetes. 34:135-139. 